\title{
Different meal, same flavor: cospeciation and host switching of haemosporidian parasites in some non-passerine birds
}

Diego Santiago-Alarcon ${ }^{1,3^{*}}$, Adriana Rodríguez-Ferraro ${ }^{2}$, Patricia G Parker ${ }^{3,4}$ and Robert E Ricklefs ${ }^{3}$

\begin{abstract}
Background: Previous studies have shown that haemosporidian parasites (Haemoproteus (Parahaemoproteus) and Plasmodium) infecting passerine birds have an evolutionary history of host switching with little cospeciation, in particular at low taxonomic levels (e.g., below the family level), which is suggested as the main speciation mechanism of this group of parasites. Recent studies have characterized diverse clades of haemosporidian parasites (H. (Haemoproteus) and H. (Parahaemoproteus)) infecting non-passerine birds (e.g., Columbiformes, Pelecaniiformes). Here, we explore the cospeciation history of H. (Haemoproteus) and H. (Parahaemoproteus) parasites with their non-passerine hosts.

Methods: We sequenced the mtDNA cyt b gene of both haemosporidian parasites and their avian non-passerine hosts. We built Bayesian phylogenetic hypotheses and created concensus phylograms that were subsequently used to conduct cospeciation analyses. We used both a global cospeciation test, PACo, and an event-cost algorithm implemented in CoRe-PA.
\end{abstract}

Results: The global test suggests that $H$. (Haemoproteus) and H. (Parahaemoproteus) parasites have a diversification history dominated by cospeciation events particularly at the family level. Host-parasite links from the PACo analysis show that host switching events are common within families (i.e., among genera and among species within genera), and occasionally across different orders (e.g., Columbiformes to Pelecaniiformes). Event-cost analyses show that haemosporidian coevolutionary history is dominated by host switching and some codivergence, but with duplication events also present. Genetic lineages unique to raptor species (e.g., FALC11) commonly switch between Falconiformes and Strigiformes.

Conclusions: Our results corroborate previous findings that have detected a global cospeciation signal at the family taxonomic level, and they also support a history of frequent switching closer to the tips of the host phylogeny, which seems to be the main diversification mechanism of haemosporidians. Such dynamic host-parasite associations are relevant to the epidemiology of emerging diseases because low parasite host specificity is a prerequisite for the emergence of novel diseases. The evidence on host distributions suggests that haemosporidian parasites have the potential to rapidly develop novel host-associations. This pattern has also been recorded in fish-monogenean interactions, suggesting a general diversification mechanism for parasites when host choice is not restricted by ecological barriers.

Keywords: Cospeciation, Haemoproteus, Haemosporida, Host switching, Non-passerines

\footnotetext{
* Correspondence: diego.santiago@inecol.mx

'Instituto de Ecología A.C., Biología y Conservación de Vertebrados, Carretera

Antigua a Coatepec 351, El Haya. C.P., Veracruz, Xalapa 91070, Mexico

${ }^{3}$ Department of Biology, University of Missouri-St. Louis, One University Blvd.,

Saint Louis MO 63121, USA

Full list of author information is available at the end of the article
}

C Biomed Central (c) 2014 Santiago-Alarcon et al.; licensee BioMed Central Ltd. This is an Open Access article distributed under the terms of the Creative Commons Attribution License (http://creativecommons.org/licenses/by/4.0), which permits unrestricted use, distribution, and reproduction in any medium, provided the original work is properly credited. The Creative Commons Public Domain Dedication waiver (http://creativecommons.org/publicdomain/zero/1.0/) applies to the data made available in this article, unless otherwise stated. 


\section{Background}

During the last decade, cophylogenetic studies on different groups of parasites have shown that the degree of association between host and parasite phylogenies depends on the nature of the interaction, including mode of transmission and dispersal capacity [1-5]. Although parasitologists long believed that avian haemosporidian parasites (including Haemoproteus (Parahaemoproteus) and Plasmodium) were host specific [6,7], recent studies have shown that haemosporidian parasites infecting passerine birds have an evolutionary history of host switching with little codivergence [2,8-12]. Nonetheless, host specificity at higher host taxonomic levels (e.g., families) has been observed for haemosporidian parasites of higher avian host taxa, such as the vireos (family Vireonidae) [13]. The low host specificity and high pathogenicity of some of these parasites has drawn attention in recent years to the study of avian haemosporidians, especially in light of other emerging infectious diseases that can spill over from bird hosts to novel hosts [e.g., 14-20].

The phylogenetic relationships among avian haemosporidians are reasonably well understood [21,22]. Recently, we have detected well-supported and highly diverse monophyletic clades of haemosporidians (e.g., H. (Haemoproteus)) that infect non-passerines [23-26]. These findings are in agreement with the traditional taxonomy of parasites infecting non-passerines [e.g., Columbiformes, 27-29]. In addition, a group of parasites of the subgenus $H$. (Parahaemoproteus) have been found to infect nonpasserines, in particular raptors and sea birds [23,30,31]. However, cophylogenetic relationships between nonpasserines and their Haemoproteus parasites are unexplored. In this study, we used mtDNA cyt b to analyze the cospeciation history of $H$. (Haemoproteus) and $H$. (Parahaemoproteus) with their non-passerine hosts. Following results of previous studies on passerine haemosporidians [2,9], we expected that Haemoproteus parasites infecting non-passerines are characterized by a cospeciation history at the family or higher taxonomic levels, and by a dynamic host switching pattern at the genus and species levels within families.

Most details of avian taxonomy are well established, but species concepts in the case of haemosporidian parasites are controversial $[2,32,33]$, despite recent advances using in vitro hybridization experiments of different haemosporidian morphological species [e.g., 34]. Current species names for haemosporidian parasites are based primarily on morphological traits [27], but, in some cases, a variety of genetic lineages representing the same morphological species have been identified [e.g., 28,35]. Perkins [32] suggested that $3 \% \mathrm{mtDNA}$ cyt b sequence divergence or more would be indicative of different morphological species based on her studies of lizard Plasmodium. Subsequently, Hellgren et al. [35] suggested that a genetic difference larger than $5 \%$ in the cyt b gene corresponds to morphologically differentiated haemosporidian parasites [e.g., 28]. However, this rule is not supported in the opposite direction, where morphologically differentiated haemosporidians occur with genetic differences less than 5\% [36,37]. Bensch et al. [33] used nuclear and mtDNA loci and proposed that haplotypes identified by the use of cyt $\mathrm{b}$ might represent reproductively isolated entities. Their conclusion was based on the significant statistical association or parallel evolution of both nuclear and mitochondrial genes and on linkage disequilibrium between lineages, even when their hosts were sympatric [33]. Hence, because morphological species can represent a diversity of independently evolving genetic lineages, we regard haemosporidian mtDNA cyt b lineages as independently evolving entities, or species, in this study, recognizing that some closely related lineages might represent genetic variation within species [38].

\section{Methods}

We used mtDNA cyt b sequences of haemosporidian parasites (subgenus Haemoproteus and Parahaemoproteus) from previous studies [23-26,30,31,39] that are either attached to a morphologically identified species or that are haplotypes belonging to a well supported phylogenetic clade (e.g. lineage GQ395631). We sequenced the mtDNA cyt $b$ for avian hosts that were not available from GenBank $^{\text {ma }}$ and for which we had blood samples, using primers L14841 [40] and H4a [41] to amplify ca. 1045 bp of mtDNA cyt b of bird hosts. PCR conditions were as described in [42]. When several bands were present in the amplified products, we optimized the reaction and then purified the targeted fragment by using QIAquick gel extraction kit (QIAGEN). If a single band was obtained, we cleaned the PCR product using Antarctic phosphatase and Exonuclease I (\#M0289S and \#M0293S respectively, New England Bio Labs, Inc.). We either used an ABI 3100 microcapillary genetic analyzer to sequence DNA products or sent the samples for sequencing at Macrogen, Inc. (Seoul, Korea). When host mtDNA cyt b sequences were not available from GenBank ${ }^{\text {tw }}$ and we did not have a DNA sample, we substituted a sequence of a closely related species from the same genus (e.g. Alcedo atthis substituted A. leucogaster, Strix butleri substituted S. seloputo).

Sequences were edited in SeqManII version 4 (19891999. DNASTAR, Inc.) and aligned by eye in Se-Al v2.0a11 (1996-2002, http://tree.bio.ed.ac.uk/software/seal/). Phylogenetic hypotheses were constructed using the program MrBayes v3.1.2 [43]. Two independent runs were made, with 4 chains in each run for a total of 1 million generations, sampling every 100 generations. The first 5000 trees (50\%) were discarded as the 'burn-in'. In total, 5000 trees from each run were used to build our majority-rule consensus tree. A TIM2 + G model of molecular evolution was 
used for parasites with shape parameter $\alpha=0.26$, and a TPM3uf + I + G model for hosts with shape parameter $\alpha=$ 0.75 and proportion of invariable sites Pinvar $=0.47$, as suggested by jModelTest v2.1.2 $[44,45]$. To implement the two models in Mr. Bayes we used the two parameter model $($ Nst $=2)$ for parasites and the next more complex available model (GTR, Nst $=6$ ) for hosts, as recommended in the user's manual; finally, we fixed the parameters (gamma shape parameter, proportion of invariable sites, nucleotide frequencies, nucleotide substitution rates) according to the values calculated with jModelTest for each case. Parasite trees were rooted using a lineage (accession number: JX993047) from the Plasmodium relictum morphospecies. Although some phylogenetic reconstructions have shown a paraphyletic relationship between the subgenera Haemoproteus and Parahaemoproteus [22,23], more recent analyses have shown that the two Haemoproteus subgenera are reciprocally monophyletic and sister to Plasmodium parasites $[28,46,47]$, validating our outgroup selection. The host tree was rooted using a sequence (accession number: AY283492) from Amazona albifrons (Psittaciformes), and phylogenetic relationships of hosts were verified following [48]. New sequences were deposited in GenBank ${ }^{\mathrm{Tx}}$ for both parasites [GenBank: KF924042] and birds [GenBank: KF924043, KF924044, KF924045, KF924046].

For cospeciation analyses, we first used PACo, a global test implemented in R [49] that uses an approach similar to ParaFit [50]. This test was used to quantitatively assess the congruence between two phylogenies, and to identify the associations (i.e., host-parasite links) contributing to the cophylogenetic structure [49]. PACo requires three matrices, one where host (rows) - parasite (columns) associations are indicated as presence/absence (host-parasite links), and two genetic distance matrices, which are calculated from the host and parasite phylogenetic trees. The host-parasite link matrix is transformed into an identity matrix to accommodate multiple associations (e.g., hosts harboring more than one parasite species/lineage and vice versa) and the two distance matrices are transformed into matrices of principal coordinates (PCo). Next, Procrustes analysis is applied using least-squares superimposition to yield a residual sum of squares $m_{X Y}^{2}$ (i.e., to determine the fit of the parasite $\mathrm{PCo}$ onto the host $\mathrm{PCo}$ ), which is inversely proportional to the topological congruence between the parasite and host PCos. Hence, $m_{X Y}^{2}$ is a measure of the fit of the parasite phylogeny onto the host phylogeny, providing a goodness-of-fit statistic whose significance is established by a randomization procedure. In our case, significance was assessed comparing the observed $m_{X Y}^{2}$ to those generated by 10,000 random permutations $\left(m_{X Y}^{2}\right)$ of the host-parasite association matrix (hosts were randomly allocated to parasites). PACo then tests the null hypothesis
$\left(\mathrm{H}_{0}\right)$ that parasite clades are randomly associated with host clades: the one-tailed probability $P$ is the proportion of $m_{X Y^{*}}^{2}$ values $\leq m^{2}{ }_{X Y}$. We also assessed the contribution of individual host-parasite associations to the global fit using the fact that $m_{X Y}^{2}$ is the sum of squared residuals of each host-parasite link $e_{i}{ }^{2}$, which provides a direct measure of the importance of each link. The $e_{i}^{2}$ 's and their 95\% confidence intervals were estimated using a jackknife method. Each $i^{\text {th }}$ link is replaced by 0 (i.e., we eliminate that specific host-parasite association from our matrix), then we estimate the $e_{i}^{2}$ squared residual for each hostparasite link to assess its contribution to the global cospeciation fit; and those links that contribute relatively little to $m_{X Y}^{2}$ likely represent coevolutionary links [see 49 for more details].

We then used CoRe-PA v0.5.1 [51], which performs an event-cost-based analysis. Such an approach aimed to find the most probable coevolutionary history (i.e., all feasible solutions to the host-parasite reconciliation problem) of the associated taxa using the parsimony criterion (i.e., lowest cost), via exhaustive searches based on an event-cost scheme. Unlike global tests, event-cost methods try to identify the type of evolutionary events (i.e., cospeciation, sorting, duplication, and switching) explaining the most parsimonious solutions. We used 100 randomizations of host-parasite associations to determine whether the number of each event type differed significantly from random associations between the two trees [51]. We used an event-cost scheme similar to previous studies to make our results comparable (Table 1). Also, because most eventcost software programs are designed to maximize the number of cospeciation events, we set the cost for codivergence low and then implemented different costs for the other three evolutionary processes (duplication, sorting, switching) implemented in the program to determine their relative contributions. These algorithms can find more than one optimal solution for the same event-cost scheme, in which case we present results for the solutions that maximize both the number of cospeciation events and the number of host switches. Host switches are expected to be more common among closely related hosts due to similarities in physiological traits [e.g., immunology, 15], but most parasite switches do not result in successful infections and novel hosts are commonly dead-end organisms for parasites [52]. Accordingly, we implemented a cost scheme for host switching events decreasing from difficult $($ cost $=3)$ to easy $(\operatorname{cost}=0)$.

\section{Results}

Parasite phylogenies were obtained in previous studies [23-25]. Here we used pruned versions of those phylogenetic trees for cospeciation analyses; consensus phylograms were calculated using unique haplotypes from well-supported clades. The avian host phylogeny was 


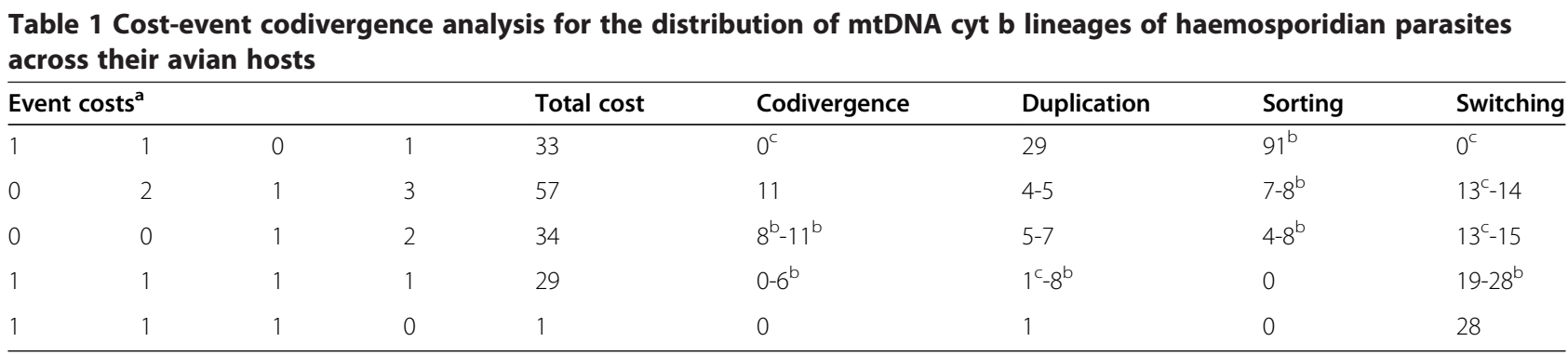

For each analysis we conducted 100 randomizations to determine whether the predicted number of each event type is higher or lower than expected by chance. aEvent costs are for codivergence (cospeciation), duplication (within-host speciation), sorting (extinction), and host switching, respectively.

${ }^{\mathrm{b}}$ The number of events significantly exceeds that for randomized trees $(\mathrm{P}<0.05)$.

'The number of events is significantly less than that for randomized trees $(P<0.05)$.

well supported and is in agreement with the phylogenomic study of birds from [48]. Relationships among Columbiformes followed that suggested by [53]. Consensus phylograms for both parasites and hosts are presented along with their tanglegram depicting host-parasite associations (Figure 1).

We detected a significant global signal of cospeciation between Haemoproteus (Haemoproteus and Parahaemoproteus) parasites and their non-passerine hosts $\left(m_{X Y}^{2}=\right.$ $2.3, P<<0.0001)$. The global cospeciation signal is mostly due to three groups: 1) host-parasite links involving pigeons and doves infected by several lineages of the morphospecies $H$. multipigmentatus, 2) host-parasite links involving frigate birds infected by lineages of the morphospecies $H$. iwa, and 3) host-parasite links involving raptors from the genera Strix and Bubo infected with lineages $H$. (Parahaemoproteus) SPOW4 and H. (Parahaemoproteus) syrnii (see light gray boxes in Figure 2). A second group contributing to the significant global cospeciation signal, albeit to a lesser degree (i.e. cospeciation patterns are less congruent compared to links in light gray boxes), includes pigeon and doves infected with lineages of $H$. columbae, $H$. paramultipigmentatus, $H$. multipigmentatus, and $H$. multivolutinus (dark gray boxes in Figure 2). Host-parasite links show that host switching is frequent within families (i.e., among genera and among species within genera), and occasionally across different orders (e.g., Columbiformes to Pelecaniiformes, Falconiformes to Strigiformes Figures 1 and 2).

Event-cost analyses showed that statistically wellsupported event combinations ranged between 29 and 57 events total cost (Table 1). The events suggest an evolutionary history dominated by host switching and some codivergence, with a lesser influence of duplication events (Table 1, event-costs 0012 and 1111). Even when we make host switching a costly event (event-costs 0213 and 0012), our analysis identified host switching as a prominent mechanism in the evolutionary history of haemosporidians.

Among the novel relationships identified in this analysis, parasite lineage CHI_30PA, which infects a Zenaida macroura dove, belongs to the well suppoted H. (Parahaemoproteus) subgenus (Figure 1). We conducted a sequence similarity analysis (BLAST algorithm of the NCBI database) between our lineage CHI_30PA and those identified by [47]. We found that our Z. macroura dove parasite lineage (sample from Chicago, USA) is $99 \%$ similar to several lineages infecting raptors sampled in California (e.g. GenBank EU627839 and EU627842). The H. turtur lineage infecting Streptopelia doves identified by [47] is sister to the $H$. sacharovi lineage infecting $Z$. macroura doves (Figure 1). All other parasites infecting pigeons and doves included in this analysis belong to the subgenus Haemoproteus (Figure 1).

\section{Discussion}

Ricklefs and Fallon [9] found that closely related haemosporidian parasites are conservatively distributed within host higher taxa, suggesting that codivergence or switching among closely related hosts is a common event in their evolutionary history $[2,54]$. In addition, duplication (within host speciation) events were modeled by TreeFitter as being frequent among these parasites when the event cost was set low [2]. By using the same gene (mtDNA cyt b) from previous studies, we have found that host switching is a commonly observed mechanism between haemosporidians and their non-passerine hosts, mainly close to the tips of the host phylogenetic tree (i.e., between close relatives). Codivergence is also observed in the evolutionary history of haemosporidian parasites infecting non-passerine birds, in particular at the family level (Figure 1). Duplication (within-host parasite lineage splitting) has also played some role in the diversification of non-passerine Haemosporida, which was also recognized in haemosporidian parasites infecting passerine birds under low event costs [2]. Even when codivergence is a prominent feature of our system, strict host specificity at the species level is rare. These findings suggest a dynamic recent evolutionary history between haemosporidians and their bird hosts, which imply that host switching, in combination with geographic isolation, might be an important mechanism in the formation of new haemosporidian 


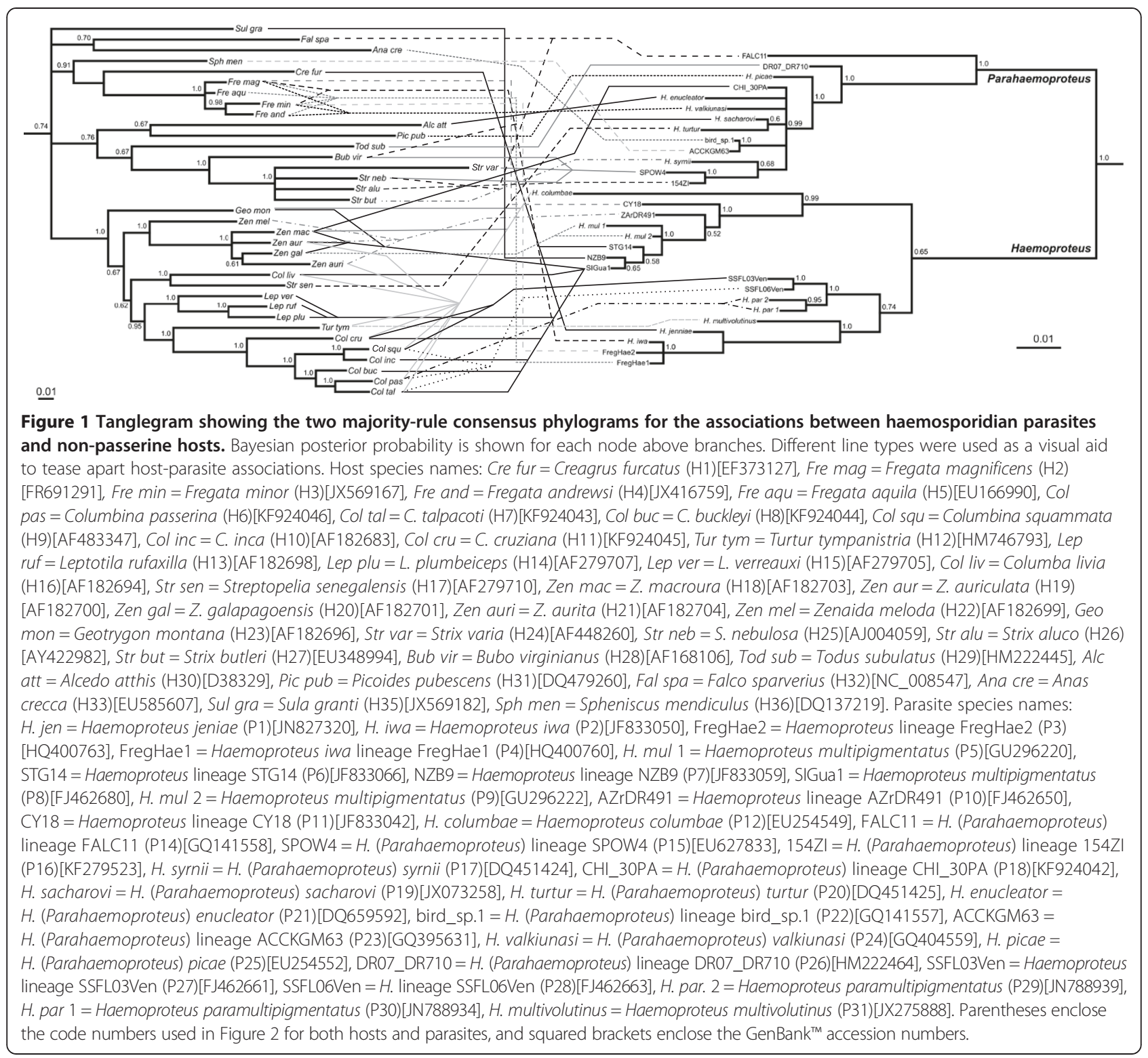

species (Ricklefs et al., unpublished). Cospeciation studies in fish-monogenean systems have also identified host switching as an important diversification mechanism aided by subsequent host isolation, producing a higher degree of specificity at the family level or above $[55,56]$. This suggests that the evolutionary history of these parasite systems is dominated by traits (e.g., immunology of hosts) that are conserved at high taxonomic levels (i.e., family or above). Where ecological barriers do not prevent parasites from switching hosts, related parasite lineages can infect distantly related hosts, as in the case of closely related Haemoproteus parasite lineages ( $H$. multipigmentatus, STG14, NZB9) infecting distantly related sea birds (e.g., Sula granti, Creagus furcatus) and doves (e.g. Zenaida galapagoensis), which occur on the same islands [25]. In the absence of such opportunities, resulting from behavioral or geographic host isolation, co-speciation might become more likely [see 55,56 for the case of fishmonogenean systems].

It is important to consider that we are leaving aside the vectors (Diptera) in this analysis of host-parasite interactions. How do haemosporidians relate coevolutionarily to dipteran vectors? It is a question for which we have almost no insight. Previous work suggests that different dipteran families are specialized in transmitting different Haemosporida genera [e.g., Ceratopogonidae transmit only Haemoproteus (Parahaemoproteus) parasites, [22,47]. Recent work on Culicidae [57-59] and Ceratopogonidae $[18,19,60,61]$ shows that many vector species have broad feeding preferences, even across 


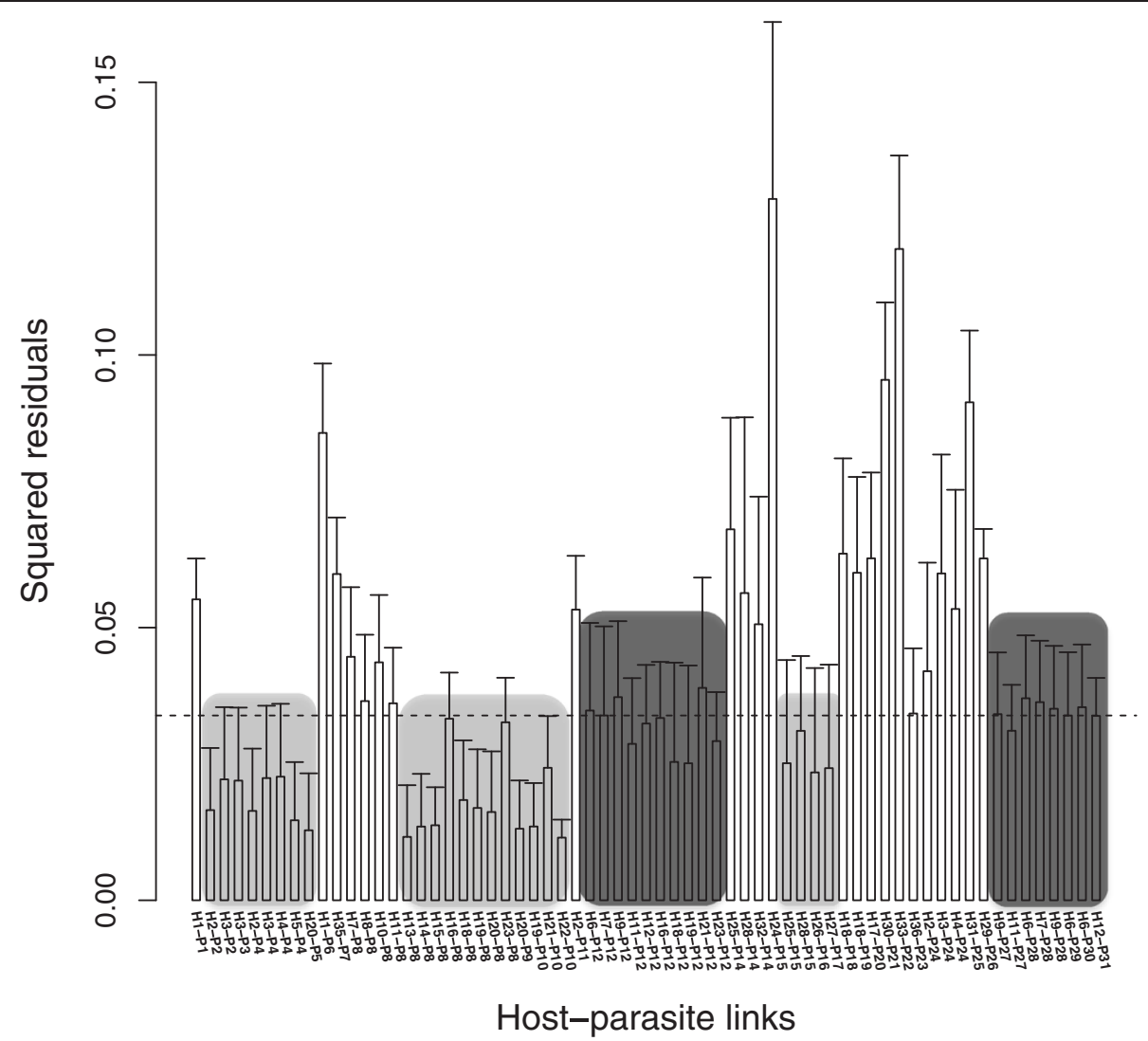

Figure 2 Contributions of individual host-parasite links to the global cospeciation fit. Jackknifed squared residuals (bars) and upper $95 \%$ confidence intervals (error bars) resulting from applying PACo to genetic distances derived from phylogenetic trees presented in Figure 1. The median squared residual value is shown (dashed line) to facilitate comparisons among different host-parasite links. Host-parasite links with low squared residual $\left(e_{i}^{2}\right)$ value likely represent coevolutionary links (see Methods). Light gray boxes indicate host-parasite links with a more important contribution to the global codivergence signal in comparison to those links enclosed by dark boxes. See Figure 1 for host-parasite links code numbers.

vertebrate classes. Thus, vectors may come in contact with a diverse array of Haemosporida parasites, including genera they do not normally transmit [e.g., 18,60,62-64]. The fact that many vector species have broad vertebrate host preferences and are susceptible to infections by different Haemosporida genera, would suggest that specificities of both vertebrate and insect host immune systems would mediate parasite "jumps" across distantly related avian hosts [see 15,64]. Experimental studies have demonstrated that an avian parasite, Plasmodium lophurae, can adapt to and be viable in mice after just four rounds of infectious inoculations [65]. Furthermore, erythrocytes of different mammal species have been shown to be susceptible to invasion by bird Plasmodium parasites [66]. Hence, these studies suggest that haemosporidian parasites could potentially adapt to phylogenetically distant hosts.

Parasites of the sub-genus Haemoproteus, which are normally transmitted by louse flies (Diptera: Hippoboscidae), might be less likely to switch between unrelated hosts because normally hippoboscid flies are host specific and do not fly long distances [67]. However, recent work in the Galapagos Islands has shown that lineages belonging to the same morphospecies (H. multipigmentatus) infect endemic doves [24,28] and sea birds inhabiting the same islands [frigate birds, gulls, brown boobies, 25], indicating host sharing by the flies even though different-sized hippoboscid species are associated with these different bird species. Furthermore, hippoboscid flies (Olfersia spinifera and $O$. aenescens) have higher rates of gene flow in comparison the their seabird hosts, which might explain the lack of genetic structure of the Haemoproteus iwa parasite across the Galápagos Islands [68]. Finally, the evolutionary history of the Hippoboscidae includes at least two host switches from mammals to birds [67], suggesting that parasites either hitchhiking with louse flies [e.g. phoretic mites, 69] or developing within them (e.g. Haemoproteus) can "jump" across large host phylogenetic distances. Hence, under the right ecological conditions (e.g. simple systems like island faunas, different bat species sharing roosts [70], similar parental care behaviour across different cichlid species [71]) parasites, in particular haemosporidians transmitted 
by hippoboscid flies, are capable of switching across distantly related hosts (see Figure 1).

Our vertebrate host sample includes species that belong to the same genera (e.g., Columbina spp., Zenaida spp.) within the same host sub-family (e.g., Columbidae: Columbinae). The distribution of parasites among host species reported here supports a degree of host specificity below the family level for parasite lineages (e.g., lineages of $H$. multipigmentatus, $H$. iwa, $H$. (Parahaemoproteus) syrnii, see Figure 1), which is validated by the cospeciation events and the global cospeciation signal detected in our system. However, that parasite haplotypes of H. (Haemoproteus) infect many species and genera within Columbiformes [24], sea birds of the same genus e.g., Fregata, [25], and host species across orders (e.g., H. (Parahaemoproteus) FALC11, Figure 1), lends support to a diversification history dominated by host switching. Our sample consists mostly of a small number of non-passerine species of the sub-family Columbinae, the genera Fregata, Creagus, Todus, Falco, Bubo, Strix, Anas, Spheniscus, Picoides, and Alcedo along with their described haemosporidian parasites, which contrasts with analyses of widely sampled passerine hosts and their parasites [see 2,9]. Thus, although our results support previous findings, a broader nonpasserine taxonomic sampling with broader geographical distribution will be required to produce a more comprehensive understanding of haemosporidian diversification.

Previous work considered that all parasites infecting Columbiformes belonged to the $H$. (Haemoproteus) subgenus $[24,28]$. However, in this study we identified a parasite lineage (CHI_30PA) from a Zenaida macroura dove that falls within the strongly supported $H$. (Parahaemoproteus) subgenus, which is in agreement with other recent examples of columbiform parasites (H. sacharovi and H. turtur) that belong to the subgenus Parahaemoproteus and likely are transmitted by Culicoides vectors [47].

\section{Conclusion}

In summary, our study shows that the codivergence history of haemosporidian parasites with their avian hosts is dominated by host switching events; cospeciation is mostly observed at the family or higher taxonomic levels [see also 2,9]. Such dynamic host-parasite associations are relevant to the epidemiology of emerging diseases. Low parasite host specificity (i.e., as shown by generalist and widely distributed parasites) is a prerequisite for the emergence of new diseases [72], and it has been observed that generalist malaria parasites reach higher prevalence than specialist parasites in the local populations they infect [e.g., 73,74]. Moreover, phylogenetically related haemosporidian lineages (e.g., sister lineages) do not necessarily have a similar host breadth and geographic distribution [74], which challenges our ability to predict novel haemosporidian zoonoses. Taken together, the evidence on host distributions suggests that haemosporidian parasites have the potential to rapidly develop novel host-associations [19], but see [64].

\section{Competing interests}

The authors declare that they have no competing interests.

\section{Authors' contributions}

Conceived and designed the study: DS-A, PGP, RER. Contributed reagents/ material/analysis tools: PGP, AR-F, DS-A. Wrote and revised critically the manuscript: DS-A, AR-F, PGP, RER. All authors have read and approved the final manuscript.

\section{Acknowledgements}

We thank all the people involve in the different parts of field work, in particular A. Iglesias, G. Buitron, J. Rabenold, J. Bollmer, I. Levin, J. Higashiguchi, J. Merkel, and S. O'Brien. We thank G.A. Sevilla-Beltrán and I. MacGregor-Fors for preparing the tanglegram. Collection of samples was done under appropriate permits from the different countries. Permits for work in the Galapagos Islands were provided by the Galapagos National Park We thank the Charles Darwin Foundation for logistical support during our work in Galapagos. This work was supported by grants to D.S.-A. from the Whitney R. Harris World Ecology Center, Idea Wild, The Frank M. Chapman Memorial Fund of the American Museum of Natural History, The Field Research for Conservation program of the Saint Louis Zoo (FRC 05-2 and FRC 08-2), and the Organization for Tropical Studies. P.G.P. was supported by the Des Lee collaborative vision in zoological studies. R.E.R. was supported by the Curators of the University of Missouri. DS-A was supported by INECOL, A.C. through project number 2000029/60816.

\section{Author details}

${ }^{1}$ Instituto de Ecología A.C., Biología y Conservación de Vertebrados, Carretera Antigua a Coatepec 351, El Haya. C.P., Veracruz, Xalapa 91070, Mexico.

2Departamento de Estudios Ambientales, Universidad Simón Bolívar, Sartenejas, Venezuela. ${ }^{3}$ Department of Biology, University of Missouri-St. Louis, One University Blvd., Saint Louis MO 63121, USA. ${ }^{4}$ WildCare Institute, Saint Louis Zoo, One Government Dr., Saint Louis, MO 63110, USA.

Received: 14 March 2014 Accepted: 7 June 2014

Published: 23 June 2014

\section{References}

1. Clayton DH, Johnson KP: Linking coevolutionary history to ecological process: doves and lice. Evolution 2003, 57:2335-2341.

2. Ricklefs RE, Fallon SM, Bermingham E: Evolutionary relationships, cospeciation, and host switching in avian malaria parasites. Syst Biol 2004, 53:111-119.

3. Balakrishnan CN, Sorenson MD: Dispersal ecology versus host specialization as determinants of ectoparasite distribution in brood parasitic indigobirds and their estrildid finch host. Mol ECO/ 2007, 16:217-229.

4. Hughes J, Kennedy M, Johnson KP, Palma RL, Page RDM: Multiple cophylogenetic analyses reveal frequent cospeciation between Pelecaniform birds and pectinopygus Lice. Syst Biol 2007, 56:232-251.

5. Whiteman NK, Kimball RT, Parker PG: Co-phylogeography and comparative population genetics of the Galápagos Hawk and three co-occurring ectoparasite species: natural history shapes population histories within a parasite community. Mol Ecol 2007, 16:4759-4773.

6. Bennett GF, Bishop MA, Peirce MA: Checklist of the avian species of Plasmodium Marchiafava and Celli, 1885 (Apicomplexa) and their distribution by avian family and Wallacean life zones. Syst Parasitol 1993, 26:171-179.

7. Bennett GF, Peirce MA, Earlé RA: An annotated checklist of the valid avian species of Haemoproteus, Leucocytozoon (Apicomplexa, Haemosporida) and Hepatozoon (Apicomplexa, Haemogregarinidae). Syst Parasitol 1994 29:61-73.

8. Bensch S, Stjernman M, Hasselquist D, Östman Ö, Hansson G, Westerdahl H, Torres PR: Host specificity in avian blood parasites: a study of Plasmodium and Haemoproteus mitochondrial DNA amplified from birds. Proc $R$ SOC $B$ 2000, 267:1583-1589.

9. Ricklefs RE, Fallon SM: Diversification and host switching in avian malaria parasites. Proc R Soc B 2002, 269:885-892. 
10. Szymanski MM, Lovette IJ: High lineage diversity and host sharing of malarial parasites in a local avian assemblage. J Parasitol 2005, 91:768-774.

11. Križanauskienė A, Hellgren O, Kosarev V, Sokolov L, Bensch S, Valkiūnas G Variation in host specificity between species of avian hemosporidian parasites: evidence from parasite morphology and cytochrome b gene sequences. J Parasitol 2006, 92:1319-1324.

12. Beadell JS, Covas R, Gebhard C, Ishtiaq F, Melo M, Schmidt BK, Perkins SL, Graves GR, Fleischer RC: Host associations and evolutionary relationships of avian blood parasites from West Africa. Int J Parasitol 2009, 39:257-266.

13. Ricklefs RE, Swanson BL, Fallon SM, Martinez-Abrain A, Scheuerlein A, Gray J, Latta SC: Community relationships of avian malaria parasites in Southern Missouri. Ecol Monogr 2005, 75:543-559.

14. Mackenzie JS, Gubler DJ, Petersen LR: Emerging flaviviruses: the spread and resurgence of Japanese encephalitis, West Nile and dengue virus. Nat Med 2004, 10:S98-S109.

15. Woolhouse MEJ, Haydon DT, Antia R: Emerging pathogens: the epidemiology and evolution of species jumps. Trends Ecol 2005, 20:238-244.

16. Kilpatrick AM, Kramer LD, Jones MJ, Marra PP, Daszak P: West Nile virus epidemics in North America are driven by shifts in mosquito feeding preferences. PLOS Biol 2006, 4:e82.

17. Jourdain E, Gauthier-Clerc M, Bicout DJ, Sabatier P: Bird migration routes and risk for pathogen dispersion into western Mediterranean wetlands. Emerg Infect Dis 2007, 13:365-372.

18. Santiago-Alarcon D, Havelka P, Schaefer HM, Segelbacher G: Blood meal analysis reveals avian Plasmodium infections and broad host preferences of Culicoides (Diptera: Ceratopogonidae) vectors. PLoS One 2012, 7:e31098.

19. Santiago-Alarcon D, Havelka P, Pineda E, Schaefer HM, Segelbacher G: Urban forests as hubs for novel zoonosis: blood meal analysis, seasonal variation in Culicoides (Diptera: Ceratopogonidae) vectors, and avian haemosporidians. Parasitology 2013, 140:1799-1810.

20. Levin I, Zwiers P, Deem SL, Geest EA, Higashiguchi JM, lezhova TA Jimenez-Uzcategui G, Kim DH, Morton JP, Perlut NG, Renfrew RB, Sari EHR, Valkiūnas G, Parker PG: Multiple lineages of avian malaria parasites (Plasmodium) in the Galapagos Islands and evidence for arrival via migratory birds. Conserv Biol 2013, 27:1366-1377.

21. Perkins SL, Schall JJ: A molecular phylogeny of malarial parasites recovered from cytochrome b gene sequences. J Parasitol 2002, 88:972-978.

22. Martinsen ES, Perkins SL, Schall JJ: A three-genome phylogeny of malaria parasites (Plasmodium and closely related genera): Evolution of life-history traits and host switches. Mol Phyl Evol 2008, 47:261-273.

23. Outlaw DC, Ricklefs RE: On the phylogenetic relationships of haemosporidian parasites from raptorial birds (Falconiformes and Strigiformes). J Parasitol 2009, 95:1171-1176.

24. Santiago-Alarcon D, Outlaw DC, Ricklefs RE, Parker PG: High lineage diversity of Haemosporidian parasites in New World doves: multiple colonization of the Galapagos Islands. Int J Parasitol 2010 40:463-470.

25. Levin I, Valkiūnas G, Santiago-Alarcon D, Cruz LL, lezhova T, O'brien SL, Hailer F, Dearborn D, Schreiber EA, Fleischer RC, Ricklefs RE, Parker PG: A new clade of Haemosporidian parasites infecting non-passerine Galapagos birds. Int J Parasitol 2011, 41:1019-1027.

26. Levin II, Valkiūnas G, lezhova TA, O'Brien SL, Parker PG: Novel Haemoproteus species (Haemosporida:Haemoproteidae) from the swallow tailed gul (Lariidae), with remarks on the host range of hippoboscid-transmitted avian hemoproteids. J Parasitol 2012, 98:847-854.

27. Valkiūnas G: Avian Malaria Parasites And Other Haemosporidia. Boca Raton: CRC Press; 2005:2005

28. Valkiūnas G, Santiago-Alarcon D, Levin I, lezhova TA, Parker PG: Haemoproteus multipigmentatus sp. nov. (Haemosporida, Haemoproteidae) from the endemic Galapagos dove Zenaida galapagoensis, with remarks on the parasite distribution, vectors, and molecular diagnostics. J Parasitol 2010, 96:783-792.

29. Valkiūnas G, lezhova TA, Evans E, Carlson JS, Martínez-Gómez JE, Sehgal RNM: Two new Haemoproteus species (Haemosporida: Haemoproteidae) from columbiform birds. J Parasitol 2013, 99:513-521.

30. Merino S, Hennicke J, Martínez J, Ludynia K, Torres R, Work TM, Stroud S, Masello JF, Quillfeldt P: Infection by Haemoproteus parasites in four species of frigatebirds and the description of a new species of Haemoproteus (Haemosporida: Haemoproteidae). J Parasitol 2012, 98:388-397

31. Karadjian G, Puech M-P, Duval L, Chavatte J-M, Snounou G, Landau I: Haemoproteus syrnii in Strix aluco from France: morphology, stages of sporogony in a hippoboscid fly, molecular characterization and discussion on the identification of Haemoproteus species. Parasite 2013, 20:32.

32. Perkins SL: Species concepts and malaria parasites: detecting a cryptic species of Plasmodium. Proc R Soc B 2000, 267:2345-2350.

33. Bensch S, Perez-Tris J, Waldenstrom J, Hellgren O: Linkage between nuclear and mitochondrial DNA sequences in avian malaria parasites: multiple cases of cryptic speciation? Evolution 2004, 58:1617-1621.

34. Valkiūnas $G$, lezhova TA, Križanauskienè A, Palinauskas V, Bensch S: In vitro hybridization of Haemoproteus spp.: an experimental approach for direct investigation of reproductive isolation of parasites. J Parasitol 2008, 94:1385-1394

35. Hellgren $\mathrm{O}$, Križanauskienė A, Valkiūnas $\mathrm{G}$, Bensch S: Diversity and phylogeny of mitochondrial cytochrome $b$ lineages from six morphospecies of avian Haemoproteus (Haemosporida, Haemoproteidae). J Parasitol 2007, 93:889-896.

36. Escalante AA, Freeland DE, Collins WE, Lal AA: The evolution of primate malaria parasites based on the gene encoding cytochrome $b$ from the linear mitochondrial genome. Proc Natl Acad Sci U S A 1998, 95:8124-8129.

37. Križanauskienè A, Pérez-Tris J, Palinauskas V, Hellgren $O$, Bensch S, Valkiūnas $\mathrm{G}$ : Molecular phylogenetic and morphological analysis of haemosporidian parasites (Haemosporida) in a naturally infected European songbird, the Blackcap Sylvia atricapilla, with description of Haemoproteus pallidulus sp. nov. Parasitology 2010, 137:217-227.

38. Svensson-Coelho M, Blake JG, Loiselle BA, Penrose AS, Parker PG, Ricklefs RE: Diversity, prevalence, and host specificity of avian Plasmodium and Haemoproteus in a Western Amazon assemblage. Ornithol Monogr 2013, 76:1-47

39. Martinsen ES, Paperna I, Schall JJ: Morphological versus molecular identification of avian Haemosporida: an exploration of three species concepts. Parasitology 2006, 133:279-288.

40. Kocher TD, Thomas WK, Meyer A, Edwards SV, Pääbo S, Villablanca FX, Wilson AC: Dynamics of mitochondrial DNA evolution in animals: amplification and sequencing with conserved primers. Proc Natl Acad SCi U S A 1989, 86:6196-6200.

41. Harshman J: Phylogeny, Evolutionary Rates, And Ducks. Phd Diss. Chicago: Univ. Chicago; 1996

42. Johnson KP, Clayton DH: A molecular phylogeny of the dove genus Zenaida: mitochondrial and nuclear DNA sequences. Condor 2000, 102:864-870.

43. Huelsenbeck JP, Ronquist F: MRBAYES: Bayesian inference of phylogeney. Bioinformatics 2001, 17:754-755.

44. Guindon S, Gascuel O: A simple, fast, and accurate algorithm to estimate large phylogenies by maximum likelihood. Syst Biol 2003, 52:696-704.

45. Darriba D, Taboada GL, Doallo R, Posada D: jModelTest 2: more models, new heuristics and parallel computing. Nat Methods 2012, 9:772-772.

46. Outlaw DC, Ricklefs RE: Rerooting the evolutionary tree of malaria parasites. Proc Natl Acad Sci U S A 2011, 108:13183-13187.

47. Križanauskienė A, lezhova TA, Sehgal RNM, Carlson JS, Palinauskas V, Bensch S, Valkiūnas G: Molecular characterization of Haemoproteus sacharovi (Haemosporida, Haemoproteidae), a common parasite of columbiform birds, with remarks on classification of haemoproteids of doves and pigeons. Zootaxa 2013, 3613:85-94.

48. Hackett SJ, Kimball RT, Reddy S, Bowie RCK, Braun EL, Braun MJ, Chojnowski JL, Cox WA, Han K-L, Harshman J, Huddleston CJ, Marks BD, Miglia KJ, Moore WS, Sheldon FH, Steadman DW, Witt CC, Yuri T: A phylogenomic study of birds reveals their evolutionary history. Science 2008, 320:1763-1768.

49. Balbuena JA, Míguez-Lozano R, Blasco-Costa I: PACo: a novel procrustes application to cophylogenetic analysis. PLoS One 2013, 8:e61048.

50. Legendre $P$, Desdevises $Y$, Bazin E: A statistical test for host-parasite coevolution. Syst Biol 2002, 51:217-234.

51. Merkle D, Middendorf M, Wieseke N: A parameter-adaptive dynamic programming approach for inferring cophylogenies. BMC Bioinformatics 2010, 11(Suppl I):S60.

52. Ewald PW: Evolution of Infectious Disease. New York: Oxford University Press; 1994. 
53. Pereira SL, Johnson KP, Clayton DH, Baker AJ: Mitochondrial and nuclear DNA sequences support a Creataceous origin of Columbiformes and a dispersal-driven radiation in the Paleogene. Syst Biol 2007, 56:656-672.

54. Fallon SM, Bermingham E, Ricklefs RE: Host specialization and geographic localization of avian malaria parasites: a regional analysis in the Lesser Antilles. Am Nat 2004, 165:466-480.

55. Desdevises Y, Morand S, Jousson O, Legendre P: Coevolution between Lamellodiscus (Monogenea: Diplectanidae) and Sparidae (Teleostei): the study of a complex host-parasite system. Evolution 2002, 56:2459-2471.

56. Desdevises $Y$ : Cophylogeny: insights from fish-parasite systems. Parassitologia 2007, 49:41-42.

57. Njabo KY, Cornel AJ, Bonneaud C, Toffelmier E, Sehgal RNM, Valkiūnas G, Russell AF, Smith TB: Nonspecific patterns of vector, host and avian malaria parasite associations in a central African rainforest. Mol Ecol 2011, 20:1049-1061.

58. Jansen CC, Webb CE, Graham GC, Craig SB, Zborowski P, Ritchie SA, Russell $R C$, van den Hurk AF: Blood sources of mosquitoes collected from urban and peri-urban environments in Eastern Australia with species-specific molecular analysis of avian blood meals. Am J Trop Med Hyg 2009, 81:849-857.

59. Kim KS, Tsuda Y, Yamada A: Bloodmeal identification and detection of avian malaria parasite from mosquitoes (Diptera: Culicidae) inhabiting coastal areas of Tokyo Bay, Japan. J Med Entomol 2009, 46:1230-1234.

60. Martínez de la Puente J, Martínez J, Rivero-de Aguilar J, Herrero J, Merino S: On the specificity of avian blood parasites: revealing specific and generalist relationships between haemosporidians and biting midges. Mol Ecol 2011, 20:3275-3287.

61. Santiago-Alarcon D, Palinauskas V, Schaefer HM: Diptera vectors of avian haemosporidian parasites: untangling parasite life cycles and their taxonomy. Biol Rev Camb Philos Soc 2012, 87:928-964.

62. Ishtiaq F, Guillaumot L, Clegg SM, Phillimore B, Black RA, Owens IPF, Mundy $\mathrm{NI}$, Sheldon BC: Avian haematozoan parasites and their associations with mosquitoes across Southwest Pacific Islands. Mol Ecol 2008, $17: 4545-4555$

63. Medeiros $\mathrm{MCl}$, Hamer GL, Ricklefs RE: Host compatibility rather than vector-host-encounter rate determines the host range of avian Plasmodium parasites. Proc R SOC B 2013, 280:20122947.

64. Valkiūnas G, Kazlauskienè A, Bernotienè R, Palinauskas V, lezhova TA: Abortive long-lasting sporogony of two Haemoproteus species (Haemosporida, Haemoproteidae) in the mosquito Ochlerotatus cantans, with perspectives on haemosporidian vector research. Parasitol Res 2013, 112:2159-2169.

65. McGhee RB: The adaptation of the avian malaria parasite Plasmodium lophurae to a continuous existence in infant mice. J Infect Dis 1951, 88:86-97.

66. McGhee RB: Comparative susceptibility of various erythrocytes to four species of avian Plasmodia. J Infect Dis 1957, 100:92-96.

67. Petersen FT, Meier R, Kutty SN, Wiegmann BM: The phylogeny and evolution of host choice in the Hippoboscoidea (Diptera) as reconstructed using four molecular markers. Mol Phyl Evol 2007, 45:111-122.

68. Levin II, Parker PG: Comparative host-parasite population genetic structures: obligate fly ectoparasites on Galapagos seabirds. Parasitology 2013, 140:1061-1069.

69. Whiteman NK, Sánchez P, Merkel J, Klompen H, Parker PG: Cryptic host specificity of an avian skin mite (Epidermoptidae) vectored by louse flies (Hippoboscidae) associated with two endemic Galápagos bird species. J Parasitol 2006, 92:1218-1228.

70. Olival KJ, Dick CW, Simmons NB, Morales JC, Melnick DJ, Dittmar K, Perkins SL, Daszak P, DeSalle R: Lack of population genetic structure and host specificity in the bat fly, Cyclopodia horsfieldi, across species of Pteropus bats in Southeast Asia. Parasites Vectors 2013, 6:231.

71. Mendlová M, Šimková A: Evolution of host specificity in monogeneans parasitizing African cichlid fish. Parasites Vectors 2014, 7:69.

72. Preiser W: Sars: A Case Study For Factors Driving Disease Emergence. In New Directions In Conservation Medicine: Applied Cases Of Ecological Health Edited by Aguirre AA, Ostfeld RS, Daszak P. New York: Oxford Univ Press; 2012:213-227.
73. Hellgren O, Pérez-Tris J, Bensch S: A Jack of all trades and still a master of some: prevalence and host range in avian malaria and related blood parasites. Ecology 2009, 90:2840-2849.

74. Szöllősi $E$, Cichoń $M$, Eens $M$, Hasselquist $D$, Kempenaers B, Merino $S$, Nilsson J-Å, Rosivall B, Rytkönen S, Török J, Wood MJ, Garamszegi LZ: Determinants of distribution and prevalence of avian malaria in blue tit populations across Europe: separating host and parasite effects. J Evol Biol 2011, 24:2014-2024.

doi:10.1186/1756-3305-7-286

Cite this article as: Santiago-Alarcon et al:: Different meal, same flavor: cospeciation and host switching of haemosporidian parasites in some non-passerine birds. Parasites \& Vectors 2014 7:286.

\section{Submit your next manuscript to BioMed Central and take full advantage of:}

- Convenient online submission

- Thorough peer review

- No space constraints or color figure charges

- Immediate publication on acceptance

- Inclusion in PubMed, CAS, Scopus and Google Scholar

- Research which is freely available for redistribution

Submit your manuscript at www.biomedcentral.com/submit
C) BioMed Central 